\title{
Determination of Ochratoxin A in Bread: Evaluation of Microwave-Assisted Extraction Using an Orthogonal Composite Design Coupled with Response Surface Methodology
}

Paula Paíga \& Simone Morais \& Teresa Oliva-Teles \& Manuela Correia \& Cristina Delerue-Matos \& Ana M. M. Sousa \& Maria do Pilar Gonçalves \& Sofia C. Duarte \& Angelina Pena \& Celeste Matos Lino

\begin{abstract}
An analytical method using microwave-assisted extraction (MAE) and liquid chromatography (LC) with fluorescence detection (FD) for the determination of ochra- toxin A (OTA) in bread samples is described. A $2^{4}$ orthogonal composite design coupled with response surface methodology was used to study the influence of MAE parameters (extraction time, temperature, solvent volume, and stirring speed) in order to maximize OTA recovery. The optimized MAE conditions were the following: $25 \mathrm{~mL}$ of acetonitrile, $10 \mathrm{~min}$ of extraction, at $80^{\circ} \mathrm{C}$, and maximum stirring speed. Validation of the overall methodology was performed by spiking assays at five levels $(0.1-3.00 \mathrm{ng} / \mathrm{g})$. The quantification limit was $0.005 \mathrm{ng} / \mathrm{g}$. The established method was then applied to 64 bread samples (wheat, maize, and wheat/maize bread) collected in Oporto region (Northern Portugal). OTA was detected in $84 \%$ of the samples with a maximum value of $2.87 \mathrm{ng} / \mathrm{g}$
\end{abstract}

below the European maximum limit established for OTA in cereal products of $3 \mathrm{ng} / \mathrm{g}$.

\section{Keywords}

Ochratoxin A · Liquid chromatography · Microwave assisted extraction $\cdot$ Bread

Introduction

Ochratoxin A (OTA) is a mycotoxin mainly produced by some species of Aspergillus and Penicillium. Penicillium verrucosum is the main source of OTA in cereals and cereal products in Europe (Elmholt \& Rasmussen, 2005). Due to the ubiquitous nature of these fungal species, OTA is one of the most prevalent human contaminants in the food chain (Manique et al. 2008).

The concerns about OTA derive from its nephrotoxic, carcinogenic, teratogenic, and immunosuppressive properties (IARC 1993). Consequently, in order to reduce consumers' exposure, the European Food Safety Agency (EFSA) and the Joint FAO/WHO Expert Committee on Food Additives (JECFA) recommended maximum tolerable weekly intakes of $120 \mathrm{ng} / \mathrm{kg}$ bw/week and $100 \mathrm{ng} / \mathrm{kg}$ bw/week, respectively (EFSA, 2006; JECFA, 2007).

The occurrence of OTA in food has been reported worldwide (Juan et al. 2007, 2008a; Zinedine et al. 2007; Duarte et al. 2010a). Cereals and cereal-derived products are assumed to be the major dietary source of OTA. Bread plays an important role in the human diet and is a product of daily consumption worldwide. The World Health Organization (WHO) recommends a $250 \mathrm{~g} /$ day bread intake equivalent to $90 \mathrm{~kg} /$ person/ 
year (González-Osnaya et al. 2006). Several authors have indicated bread as one of the main sources of daily intake of OTA as a result of the contamination of cereal flour and probably because OTA is very stable and is only partly destroyed during the baking process (González-Osnaya et al. 2007). In the European Union, a maximum permitted level of OTA in cereal products has been established at $3 \mathrm{ng} / \mathrm{g}$ (EC 2005).

Several recent studies refer to the contamination of bread samples with OTA. In Portugal, nine out of fifteen maize bread samples from the central region showed OTA concentrations ranging from not detected (n.d.) to $2.65 \mathrm{ng} / \mathrm{g}$ (Juan et al. 2007). Another study reported a percentage of OTA contamination of $70 \%$ for the maize bread $(n 030)$ and $12.9 \%$ for the wheat bread samples $(n 031)$. One maize bread sample $(5.86 \mathrm{ng} / \mathrm{g})$ exceeded the European maximum limit of $3 \mathrm{ng} / \mathrm{g}$ (Juan et al. 2008b).

González-Osnaya et al. (2007) reported that the incidence of OTA in bread samples from Spain varied between $20.3 \%$ and $23.0 \%$ for non-organic ( $n$ 074) and organic bread ( $n$ 026), respectively; five samples exceeded the European maximum permitted limit. Estimated daily intake of OTA in this study was $1.6 \mathrm{ng} / \mathrm{kg}$ bw/day. A review by Duarte et al. (2010a) presents a critical analysis on OTA occurrence reported by recent studies worldwide focusing both on unprocessed and processed cereal foodstuffs, namely flour, bread, breakfast cereals, and baby/infant foods.

The analysis of OTA from cereal and bread samples is mainly accomplished using solvent extraction and clean-up with immunoaffinity columns (IAC) (Juan et al. 2007), although other extraction and clean-up techniques have been employed, such as ion exchange columns (Pelegri et al. 1997), matrix solid phase dispersion (MSPD) with C8 (Zinedine et al. 2007; Juan et al. 2008a), solid-phase microextraction (SPE) with C18 (Vega et al. 2009), molecularly imprinted solid phase extraction (MISPE) (Ali et al. 2010), accelerated solvent extraction (ASE) (González-Osnaya et al. 2007), pressurized liquid extraction (PLE) (GonzálezOsnaya et al. 2006; Liazid et al. 2007), and supramolecular solvent-based microextraction (García-Fonseca et al.2010). The analytical methods for the determination of mycotoxins are discussed in recent reviews by Turner et al. (2009) and Duarte et al. (2011). So far, IAC surpasses other reported clean-up methods in versatility, selectivity, and reproducibility. However, IAC presents important disadvantages for routine analysis since columns are expensive, not recyclable, have a limited storage time and, in some cases, show crossreactivity with ochratoxin C (García-Fonseca et al. 2010). Therefore, alternative extraction and clean-up methods that can overcome these disadvantages are necessary.

Microwave-assisted extraction (MAE) is one of the techniques developed to reduce the volume of solvents required, improve the recovery and precision of analytes, and decrease analysis costs (Liazid et al. 2007). To our knowledge,
MAE has been scarcely applied in the analysis of mycotoxins. Pallaroni and Von Holst have studied the use of MAE in the determination of zearalenone from wheat and corn samples (Pallaroni et al. 2002; 2003). More recently, Liazid et al. (2007) compared the stability of OTA solutions under different extraction techniques, namely, MAE, PLE, ultrasound-assisted and magnetic stirring-assisted extraction. They have concluded that OTA can be extracted without degradation at temperatures up to $150{ }^{\circ} \mathrm{C}$, using MAE, and up to $100{ }^{\circ} \mathrm{C}$, using PLE, for extraction times of $20 \mathrm{~min}$.

For detection and quantification of OTA and mycotoxins in general, the methods are based on thin layer chromatography (TLC), enzyme-linked immunosorbent assay (ELISA), liquid chromatography with electrospray ionization tandem mass spectrometry (LC-ESI/MS/MS), and mainly liquid chromatography with fluorescence detection(LC-FD). LC-FD has lower detection limits (LOD) and is less expensive than MS and hence, LC-FD is the most widely used analytical detection method for OTA (Turner et al. 2009; García-Fonseca et al. 2010; Duarte et al. 2011).

The goal of this study was to optimize the conditions for the MAE of OTA from bread samples using response surface methodology (RSM). As many factors can influence OTA recovery, response surface methodology was applied to fit and exploit the mathematical model representing the relationship between the response (extraction recovery) and input variables (extraction time, temperature, solvent volume and stirring speed) (Montgomery, 2005). The optimized method was used in a survey performed in the Oporto region (Northern Portugal) involving a total of 64 bread samples.

\section{Material and Methods}

Reagents and Solutions

Acetonitrile (Lichrosolv, Merck, Darmstadt, Germany), glacial acetic acid (assay $\geq 99.7 \%$, Carlo Erba, Rodano, USA), hydrochloric acid $37 \%$ (Panreac, Barcelona, Spain), ammonia $25 \%$ (Panreac, Barcelona, Spain), methanol (Lichrosolv, Merck, Darmstadt, Germany), $n$-hexane (Unisolv, Merck, Darmstadt, Germany), ethanol absolute (Panreac, Barcelona, Spain), acetone ( $\geq 99.8 \%$, Carlo Erba, Rodano, USA), and petroleum ether $40-60{ }^{\circ} \mathrm{C}$ (Panreac, Barcelona, Spain) were used. OTA ( $\geq 98 \%$ purity) was purchased from Sigma Chemical Co. (St. Louis, MO, USA). Ultra-pure water $(18.2 \mathrm{M} \Omega \mathrm{cm})$ was produced by a Simplicity 185 apparatus (Millipore, Molsheim, France).

A standard stock solution was prepared by dissolving OTA with $95 \%$ acetonitrile and $5 \%$ water solution $\mathrm{pH} 2.60$ (adjusted with acetic acid) at $250 \mu \mathrm{g} / \mathrm{mL}$ and stored at $-20{ }^{\circ} \mathrm{C}$. Intermediate standard solutions were prepared weekly at $10 \mu \mathrm{g} / \mathrm{mL}$. For calibration curves, six standard 
solutions $(0.5-10.0 \mu \mathrm{g} / \mathrm{L})$ were prepared in $95 \%$ acetonitrile and $5 \%$ water solution $\mathrm{pH} 2.60$ (adjusted with acetic acid). Amber glassware was used to prevent light deterioration of the mycotoxin.

Sampling

A total of 64 bread samples of different types (wheat bread, maize bread, and traditional "broa de Avintes" (half maize half rye composition)) were purchased from markets, baker's shops, and hypermarkets in Oporto region. Samples were collected between the winter of 2008 and the winter of 2010 (ten samples) and in the summer of 2010 (54 samples). Milled subsamples of $100 \mathrm{~g}$ each were stored in plastic bags at $-20{ }^{\circ} \mathrm{C}$ until analysis. All labelled information was registered. Moisture was determined in the fresh bread samples using a MLS moisture analyzer from Kern (Balingen, Germany).

Microwave-Assisted Extraction Procedure

MAE were performed with a 1,500-W MARS-X (Microwave Accelerated Reaction System for Extraction, CEM, Mathews, NC, USA) configured with a 14 position carousel. HP-500 Plus Teflon ${ }^{\circledR}$ PFA extraction vessels (CEM, Mathews, NC, USA) were used. During operation, both temperature and pressure were monitored in a single vessel.

For recovery studies, homogenized bread samples $(5.0 \mathrm{~g})$ were spiked at five levels $(0.10 ; 0.25 ; 0.50 ; 2.00$; and 3.00 $\left.\mathrm{ng}_{\text {OTA }} / \mathrm{g}_{\text {bread }}\right)$. The spiking volume was $300 \mu \mathrm{L}$ in all cases. Fortified and non-spiked samples were allowed to stand for 30 min before extraction preserved from the light. Recovery (percent) was calculated as the ratio between the concentration determined in the sample and the spiked concentration $\times$ $100 \%$.

Samples were extracted using different tested solvents (acetonitrile, acetonitrile:water solution $\mathrm{pH} 2.60(95: 5, v / v)$, acetonitrile:methanol $(1: 1, v / v)$, methanol, methanol:water solution $\mathrm{pH} 2.60(95: 5, v / v), n$-hexane:acetone $(1: 1, \quad v / v))$ and volumes $(20,25,30,35$, and $40 \mathrm{~mL})$, at the selected temperatures $\left(60^{\circ} \mathrm{C}, 80^{\circ} \mathrm{C}, 100{ }^{\circ} \mathrm{C}, 120^{\circ} \mathrm{C}\right.$, and $140{ }^{\circ} \mathrm{C}$ ), with constant stirring (turned off, low, medium, and high) for $5,10,15,20$ and $25 \mathrm{~min}$.

After extraction, the vessels were allowed to cool to about $30{ }^{\circ} \mathrm{C}$ before they were opened. Extracts were filtered through Whatman GF/C filters using a DINKO D-95 vacuum pump and evaporated to dryness using a rotary evaporator Büchi B-940 (Büchi, Flawil, Switzerland) connected to a Büchi Vac V-500 pump. The water bath was kept at $20{ }^{\circ} \mathrm{C}$. The residue was redissolved in $1.5 \mathrm{~mL}$ of the mixture acetonitrile:water solution $\mathrm{pH} 2.60(95: 5, v / v)$. A $1.25 \mathrm{~mL}$ aliquot was transferred to an amber vial, evaporated with a gentle stream of nitrogen to dryness, and redissolved in $125 \mu \mathrm{L}$ of acetonitrile:water solution pH02.60 (95:5, v/v). Before LC analysis, the solution was filtered through a $0.2 \mu \mathrm{m}$ PTFE syringe filter OlimPeak (Teknokroma, Barcelona, Spain).

\section{Chromatographic Analyses}

Extracts were analyzed using a Shimadzu LC system (Shimadzu Corporation, Kyoto, Japan) equipped with a LC 20AB Prominence pump, a DGU-20A5 Prominence degasser, a SIL 20A Prominence autosampler and a RF-10AXL fluorescence detector (FD). An Atlantis column (dC18, $5 \mu \mathrm{m}, 2.1 \times 150 \mathrm{~mm}$, Waters, Milford, MA, USA) was used and maintained at room temperature. Solvent A consisted of water to which $\mathrm{pH}$ was adjusted to 2.60 with acetic acid and solvent $\mathrm{B}$ was acetonitrile. The total flow rate was $0.5 \mathrm{~mL} / \mathrm{min}$. The gradient applied was as follows: 0 min, $40 \%$ B maintained for $14 \mathrm{~min} ; 18 \mathrm{~min}, 100 \% \mathrm{~B}$ maintained for $10 \mathrm{~min}$; $30 \mathrm{~min}, 40 \% \mathrm{~B}$ maintained for $5 \mathrm{~min}$. The injection volume was $15 \mu \mathrm{L}$. The fluorescence intensity was measured at the optimized excitation/emission wavelength pair, 333/460 $\mathrm{nm}$. LCsolution software version 2.1 (Shimadzu Corporation, Kyoto, Japan) was used for control and data processing.

\section{Strategy for Optimization of Microwave-Assisted} Extraction

RSM is a collection of mathematical and statistical techniques useful for the modelling and analysis of problems in which a response of interest is influenced by several variables and the objective is to optimize this response or determine the region that satisfies the operating specifications (Montgomery, 2005). This procedure involves fitting a function to the experimental data and then using optimization techniques to obtain the optimum parameters (Garg et al. 2008). In most cases, the real relation between the response and the independent variables is unknown and, usually, polynomial models are used as they give a good approximation to the true relationship of the considered variables.

The experimental domain was defined taking into account the results obtained in preliminary tests and all significant parameters in a typical MAE process were chosen: extraction time $\left(X_{1} ; \mathrm{min}\right)$, temperature $\left(X_{2} ;{ }^{\circ} \mathrm{C}\right)$, solvent volume $\left(X_{3} ; \mathrm{mL}\right)$, and stirring speed $\left(X_{4}\right.$; four positions are available in modern apparatus: turned off, minimum, medium, and maximum speed).

OTA recovery from spiked bread samples at $3.0 \mathrm{ng} / \mathrm{g}$ was the response variable studied $\left(Y_{1}\right)$. Initially, an orthogonal central composite design with four parameters, $2^{4}$, was the approach made to the optimization problem. This design included 36 experiments to estimate the model coefficients: 16 points of a factorial design at levels $\alpha 0 \pm 1,8$ axial points at a distance $\alpha 0 \pm 2$ from the center, and a center point with 
12 replications (Table 1). The 12 replicates at the centre point allowed estimating experimental error and checking the fit. Additionally, three replicates were performed for each of the remaining experimental runs minimising the error associated with measurements made under the same

conditions. Mean values of response are presented in Table 1. The results in the initial set of experiments (runs 1-16 in Table 1) were fitted to a first order model (Eq. 1; Montgomery 2005) and its adequacy was checked,

$$
Y_{\mathrm{i}}=b_{0}+\sum_{\mathrm{i}} b_{\mathrm{i}} X_{\mathrm{i}}+\sum_{\mathrm{ij}} b_{\mathrm{ij}} X_{\mathrm{i}} X_{\mathrm{j}}+\varepsilon
$$

where $Y_{\mathrm{i}}$ is the experimental response, $X_{\mathrm{i}}$ are the studied factors, $b_{0}$ is the average response, $b_{\mathrm{i}}$ are the average effects of the different factors, $b_{\mathrm{ij}}$ are the average effects of second interaction factors, and $\varepsilon$ is the experimental error. If the lack of fit was not significant, steepest ascent method was applied in order to move rapidly to the optimum region. On the contrary, if the first order model lack of fit reached significance, probably due to a quadratic effect, additional runs were performed to improve model adjustment. Then, experimental data were fitted to the following second order model (Eq. 2; Montgomery, 2005):

$$
Y_{\mathrm{i}}=b_{0}+\sum_{\mathrm{i}} b_{\mathrm{i}} X_{\mathrm{i}}+\sum_{\mathrm{ij}} b_{\mathrm{ij}} X_{\mathrm{i}} X_{\mathrm{j}}+\sum_{i} b_{\mathrm{in}} x_{\mathrm{i}}^{2}+\varepsilon
$$

where $b_{\mathrm{ii}}$ are the quadratic components. The lack of fit in the second order model is desired to be not significant and if it persists, steepest ascent method should be used.

All statistical analyses were made using the software Statistica version 8.0 (StatSoft, Inc., Tulsa, UK), namely, multifactor variance analysis (ANOVA) and response surface 3D plots. The two factors not represented by the horizontal axes were fixed at their 0 level values. Mean square (MS) residual was the error term chosen in all ANOVA tests of statistical significance.

In order to validate a model, appropriate analysis of variance (ANOVA) must be carried out (Masmoudi et al. 2008). The total sum of squares of the mathematical model is divided into the sum of squares due to the regression (SS model in Table 2) and the residual sum of squares (SS residual in Table 2). The latter, can be divided in two parts:
Table 1 Real values and coded levels for the experimental design $2^{\top}\left(X_{1}\right.$-extraction time; $\mathrm{X}_{2}$-temperature; $\mathrm{X}_{3}$-solvent volume; $\mathrm{X}_{4}$-stirring speed) and results (mean of three replicates for each run except for the center point that corresponds to the mean of 12 replicates) for the observed OTA recovery $\left(Y_{1}\right)$ trom wheat bread samples spiked at $3.0 \mathrm{ng} / \mathrm{g}$
C.P. center point; $n$.a. not available, the equipment does not have a stirring speed higher than the maximum one; $n$.d. not determined; $X_{4}$ (stirring speed)four

\begin{tabular}{|c|c|c|c|c|c|}
\hline Exp. & $X_{1}(\min )$ & $X_{2}\left({ }^{\circ} \mathrm{C}\right)$ & $X_{3}(\mathrm{~mL})$ & $X_{4}$ & $Y_{1}(\%)$ \\
\hline 1 & $10(-)$ & $80(-)$ & $25(-)$ & $1(-)$ & $69.3 \pm 0.1$ \\
\hline 2 & $10(-)$ & $80(-)$ & $25(-)$ & $3(+)$ & $81.1 \pm 0.9$ \\
\hline 3 & $10(-)$ & $80(-)$ & $35(+)$ & $1(-)$ & $80.2 \pm 0.1$ \\
\hline 4 & $10(-)$ & $80(-)$ & $35(+)$ & $3(+)$ & $77.4 \pm 2.5$ \\
\hline 5 & $10(-)$ & $120(+)$ & $25(-)$ & $1(-)$ & $80.5 \pm 2.1$ \\
\hline 6 & $10(-)$ & $120(+)$ & $25(-)$ & $3(+)$ & $80.7 \pm 2.2$ \\
\hline 7 & $10(-)$ & $120(+)$ & $35(+)$ & $1(-)$ & $74.1 \pm 1.8$ \\
\hline 8 & $10(-)$ & $120(+)$ & $35(+)$ & $3(+)$ & $78.1 \pm 0.5$ \\
\hline 9 & $20(+)$ & $80(-)$ & $25(-)$ & $1(-)$ & $77.2 \pm 1.6$ \\
\hline 10 & $20(+)$ & $80(-)$ & $25(-)$ & $3(+)$ & $76.2 \pm 2.7$ \\
\hline 11 & $20(+)$ & $80(-)$ & $35(+)$ & $1(-)$ & $67.2 \pm 0.9$ \\
\hline 12 & $20(+)$ & $80(-)$ & $35(+)$ & $3(+)$ & $73.9 \pm 1.2$ \\
\hline 13 & $20(+)$ & $120(+)$ & $25(-)$ & $1(-)$ & $79.4 \pm 2.2$ \\
\hline 14 & $20(+)$ & $120(+)$ & $25(-)$ & $3(+)$ & $77.5 \pm 0.4$ \\
\hline 15 & $20(+)$ & $120(+)$ & $35(+)$ & $1(-)$ & $71.9 \pm 2.2$ \\
\hline 16 & $20(+)$ & $120(+)$ & $35(+)$ & $3(+)$ & $70.8 \pm 1.2$ \\
\hline $17(\mathrm{CP})$ & $15(0)$ & $100(0)$ & $30(0)$ & $2(0)$ & $75.3 \pm 2.0$ \\
\hline \multicolumn{6}{|c|}{ Additional runs-model expansion } \\
\hline 18 & $5\left(-2^{4 / 4}\right)$ & $100(0)$ & $30(0)$ & $2(0)$ & $69.5 \pm 0.1$ \\
\hline 19 & $25\left(+2^{4 / 4}\right)$ & $100(0)$ & $30(0)$ & $2(0)$ & $76.4 \pm 1.2$ \\
\hline 20 & $15(0)$ & $140\left(-2^{4 / 4}\right)$ & $30(0)$ & $2(0)$ & $56.6 \pm 1.5$ \\
\hline 21 & $15(0)$ & $60\left(+2^{4 / 4}\right)$ & $30(0)$ & $2(0)$ & $75.0 \pm 1.8$ \\
\hline 22 & $15(0)$ & $100(0)$ & $20\left(-2_{4 / 4}^{4 / 4}\right)$ & $2(0)$ & $76.4 \pm 0.3$ \\
\hline 23 & $15(0)$ & $100(0)$ & $40\left(+2^{4 / 4}\right)$ & $2(0)$ & $75.4 \pm 0.4$ \\
\hline
\end{tabular}
positions available: turned off 
24

$15(0)$ and maximum speed (3)
260 (0)

15 20)(0)

10() (O) $\left.2^{4 / 4}\right)$

$207 \varnothing) 5 \pm 1.7$

n.a. $\left(+2^{4 / 4}\right)$

n.d. 
Table 2 Analysis of variance (ANOVA) of the custom built models for OTA
$S S$ sum of squares; $D F$ degree of freedom; $M S$ mean square; $R^{2}$ quadratic correlation coefficient
Factorial regression model with second order-factor interactions $-2^{4}$ full factorial design

\begin{tabular}{lll}
\hline Response & Source & SS \\
OTA, $Y_{1, \mathrm{a}}(\%)$ & Model & 591 \\
& Residual & 389 \\
& Lack of fit & 258 \\
& Pure error & 131 \\
& Total & \\
& $R^{2}$ & 0.6032 \\
& Adjusted $R^{2}$ & 0.5222
\end{tabular}

Custom built model with third order-factorial interactions

\begin{tabular}{|c|c|c|c|c|c|c|}
\hline \multirow[t]{7}{*}{ OTA, $Y_{1, \mathrm{~b}}(\%)$} & Model & 726 & 14 & 51.9 & 9.24 & $<0.00001$ \\
\hline & Residual & 253 & 45 & 5.62 & & \\
\hline & Lack of fit & 122 & 2 & 60.9 & 17.0 & $<0.00001$ \\
\hline & Pure error & 131 & 43 & 3.05 & & $<0.00001$ \\
\hline & Total & & 59 & & & \\
\hline & $R^{2}$ & 0.7418 & & & & \\
\hline & Adjusted $R^{2}$ & 0.6615 & & & & \\
\hline \multicolumn{7}{|c|}{ Second order polynomial regression model $-2^{4}$ Central composite design } \\
\hline \multirow[t]{7}{*}{ OTA, $Y_{1, \mathrm{c}}(\%)$} & Model & 1,174 & 14 & 83.8 & 5.57 & $<0.00001$ \\
\hline & Residual & 994 & 66 & 15.1 & & \\
\hline & Lack of fit & 842 & 9 & 93.6 & 35.1 & $<0.00001$ \\
\hline & Pure error & 152 & 57 & 2.66 & 31.5 & $<0.00001$ \\
\hline & Total & & 80 & & & \\
\hline & $R^{2}$ & 0.5415 & & & & \\
\hline & Adjusted $R^{2}$ & 0.4443 & & & & \\
\hline
\end{tabular}

Custom built model with third order polynomial and second order-factorial interactions

\begin{tabular}{|c|c|c|c|c|c|c|}
\hline \multirow[t]{7}{*}{ OTA, $Y_{1, \mathrm{~d}}(\%)$} & Model & 1,761 & 18 & 97.8 & 14.9 & $<0.00001$ \\
\hline & Residual & 407 & 62 & 6.56 & & \\
\hline & Lack of fit & 255 & 5 & 51.0 & 19.1 & $<0.00001$ \\
\hline & Pure error & 152 & 57 & 2.66 & 36.8 & $<0.00001$ \\
\hline & Total & & 80 & & & \\
\hline & $\mathrm{R}^{2}$ & 0.8125 & & & & \\
\hline & Adjusted $\mathrm{R}^{2}$ & 0.7580 & & & & \\
\hline
\end{tabular}

Custom built model with third order polynomial and third order-factorial interactions

\begin{tabular}{|c|c|c|c|c|c|c|}
\hline \multirow{7}{*}{ OTA, $Y_{1, \mathrm{e}}(\%)$} & Model & 1,897 & 22 & 86.2 & 18.5 & $<0.00001$ \\
\hline & Residual & 271 & 58 & 4.66 & & \\
\hline & Lack of fit & 119 & 1 & 119 & 44.7 & $<0.00001$ \\
\hline & Pure error & 152 & 57 & 2.66 & 32.4 & $<0.00001$ \\
\hline & Total & & 80 & & & \\
\hline & $R^{2}$ & 0.8751 & & & & \\
\hline & Adjusted $R^{2}$ & 0.8277 & & & & \\
\hline
\end{tabular}

one part due to pure experimental error and computed as the sum of squared deviations (SS pure error in Table 2) in the center point and remaining experiments, and the second part corresponds to the lack of fit (SS lack of fit in Table 2).

Significance of each coefficient present in regression equations, as well as studied factors and their interactions effects, was determined by the Student's $t$ test and $p$ values (a $95 \%$ confidence level was used). Factors and/or interactions with an experimental error greater than the effect ( $p$ value $>0.05$ ) were not influential. If the model did not predict a satisfactory solution, optimum conditions were obtained by surface 3D plots inspection and statistical information. All experiments were performed in randomized order to minimize bias effect. 
Results and Discussion

\section{Chromatographic Analysis}

The chromatographic conditions were optimized in order to allow for the separation of the OTA peak from the other compounds that were co-extracted using the MAE procedure. The calibration curves were obtained using the linear least squares regression procedure of the peak area versus concentration. The linearity for OTA at six concentration levels, between 0.5 and $10 \mu \mathrm{g} / \mathrm{L}$, was good as shown by the correlation coefficients $\left(R^{2} 00.9999\right)$. As regards the analysis of bread samples, quantification by standard addition was preferred considering that some interference from the matrix was observed in some of the samples, especially in the case of maize and maize/ryebread.

The detection (LOD) and quantification (LOQ) limits were 0.002 and $0.005 \mathrm{ng} / \mathrm{g}$, respectively, in the bread samples, calculated according to Miller and Miller (1989) from the standard addition calibration curve of unfortified bread samples. Globally, the attained sensitivity is appropriate for OTA screening and determination at the maximum level of $3 \mathrm{ng} / \mathrm{g}$ established in the European Union for cereal-based products.

\section{Microwave-Assisted Extraction}

This extraction technique has the main advantages of reducing sample handling and increasing sample throughput, thereby minimizing the cost of the analysis. Microwave systems also provide an excellent opportunity for automation and according to our previous studies (Paíga et al. 2008; 2009) should be appropriate, after a suitable optimization, to extract OTA from other types of samples.

\section{Preliminary Considerations}

One of the most important parameters in MAE is the extraction solvent. Several solvents and mixtures were considered in the preliminary studies (see "Microwave-assisted Extraction Procedure" section of the "Materials and Methods").

Acetonitrile was tested since it has a higher dielectric constant $\left(\varepsilon^{\prime}\right)$ than methanol which is commonly used in MAE ( $\varepsilon^{\prime}$ acetonitrile 038.2, $\varepsilon^{\prime}$ methanol 032.6 at $25{ }^{\circ} \mathrm{C}$ (Sun and Lee, 2002)). Additionally, acetonitrile is compatible with the LC-FD procedure and consequently no solvent exchange is required, reducing the loss of analytes during sample preparation.

Conventional solid-liquid extraction methods for the analysis of OTA in cereal and cereal-based products normally use a variety of mixtures of acetonitrile or methanol and water (Pallaroni et al. 2002).
In the present study, acetonitrile:water solution $\mathrm{pH} 2.60$ $(95: 5, v / v)$ was tested in MAE experiments because it proved to be the best acetonitrile:water composition for redissolving OTA extracts before LC (data not shown). The mixture methanol:water solution $\mathrm{pH} 2.60(95: 5, v / v)$ was also assessed. The inverse proportions (acetonitrile: water solution $\mathrm{pH} 2.60(5: 95, v / v)$ and methanol:water solution $\mathrm{pH} 2.60(5: 95, v / v)$ were also assessed as MAE extraction solvents. However, after MAE extraction, an emulsion was formed that did not allow the filtration of the extracts.

In preliminary tests, MAE was performed at $100{ }^{\circ} \mathrm{C}$ with constant medium stirring for $15 \mathrm{~min}$, using $30 \mathrm{~mL}$ of the selected solvents and $5.0 \mathrm{~g}$ of bread samples (wheat bread, maize bread, and half maize half rye bread ("broa de Avintes") spiked at $3.0 \mathrm{ng} / \mathrm{g}$. The best results were obtained using acetonitrile, with OTA recoveries in the range 73.7$83.5 \%$ and good relative standard deviations (RSD) (2.2$4.1 \%$ ) (Table 3). The mixture acetonitrile:water solution pH $2.60(95: 5, v / v)$ allowed slightly lower recoveries $(62.5-76.0 \%)$, while the other solvents tested gave considerably lower recoveries for OTA. Therefore, acetonitrile was the solvent selected for the subsequent optimization studies.

\section{Optimization Study}

The experimental domain and the selection of solvent were established based on the results obtained in preliminary tests. All important parameters in a typical MAE process were selected (extraction time, temperature, solvent volume and stirring speed; Table 1). The experiments were carried out with wheat bread samples spiked at $3 \mathrm{ng} / \mathrm{g}$ because this is the type of bread most consumed in Portugal (INE 2008).

Regression Model OTA recoveries from the initial set of experiments (runs $1-16$ from the $2^{4}$ full factorial design; Table 1) were fitted to a first order model revealing a very significant lack of fit $\left(R^{2} 00.2764, p<0.0001\right)$. Initially, this result was attributed to the influence of quadratic effects and so additional runs (runs 18-24 in Table 1) at a distance $\alpha 0 \pm 2$ from the center were carried out. Due to equipment experimental limitations (the equipment does not have a stirring speed higher than the maximum one), run 25 was not performed nor statistically considered by the software.

The coefficients of the coded regression model were determined according to experimental results presented in Table 1. By eliminating the non-significant parameters $(p>0.05)$, response surface regression gave the following model equation: 
Table 3 Results obtained for OTA recovery from spiked bread samples (at $3.0 \mathrm{ng} / \mathrm{g} ; n 03$ ) using different MAE extraction solvents

MAE conditions, $100{ }^{\circ} \mathrm{C}$, con-

Hexane-Acetone $(1: 1, v / v)$

\begin{tabular}{llll}
\hline Solvent & Bread type & Recovery $(\%)$ & RSD $(\%)$ \\
\hline Acetonitrile & Wheat bread & 75.8 & 2.6 \\
& Maize bread & 73.7 & 4.1 \\
& "Broa de Avintes" & 83.5 & 2.2 \\
Acetonitrile: $\mathrm{H}_{2} \mathrm{O}$ pH $2.60(95: 5, v / v)$ & Wheat bread & 62.5 & 2.9 \\
& Maize bread & 70.5 & 2.3 \\
& "Broa de Avintes" & 76.0 & 3.3 \\
Acetonitrile:methanol $(1: 1, v / v)$ & Wheat bread & 31.7 & 14.2 \\
& Maize bread & 20.8 & 9.0 \\
& "Broa de Avintes" & 11.0 & 24.2 \\
Methanol & Wheat bread & 30.4 & 20.8 \\
& Maize bread & 21.6 & 38.5 \\
& "Broa de Avintes" & 16.8 & 29.3 \\
Methanol: $\mathrm{H}_{2} \mathrm{O} \mathrm{pH} 2.60(95: 5, v / v)$ & Wheat bread & 30.7 & 14.1 \\
& Maize bread & 19.8 & 7.5 \\
& "Broa de Avintes" & 10.4 & 22.4 \\
Hexane-Acetone $(1: 1, v / v)$ & Wheat bread & 79.5 & 4.8 \\
& Maize bread & 54.1 & 14.7 \\
& "Broa de Avintes" & 27.3 & 13.6 \\
\hline
\end{tabular}
and $5 \mathrm{~g}$ of bread sample

ANOVA and RSM Analysis According to ANOVA results, $X_{2}$ and $X_{2}$ effects were the most influential parameters in OTA recovery $(p<0.0001$; Table 2$)$ with temperatures in the range $100-120{ }^{\circ} \mathrm{C}$ giving the best response (Fig. 1 and Table 1). $X_{1} X_{3}$ reached high statistical significance $(p<0.01)$ with lower solvent volumes $(20 \mathrm{~mL})$ coupled with longer ( $25 \mathrm{~min}$ ) extraction times and/or higher volumes $(40 \mathrm{~mL})$ with shorter times (5 min) producing highest recoveries (Fig. 1). OTA recovery was negatively favored by solvent volume $\left(X_{3}\right.$; $p<0.01)$ in opposition to the positive influence of the speed of agitation $\left(X_{4} ; p<0.05\right)$ being $20 \mathrm{~mL}$ of solvent and maximum speed of agitation the best options. Experimental data(Table 1) corroborated these findings with solvent volume at minimum level in the full factorial design $(25 \mathrm{~mL}$; runs $1-16$ in Table 1$)$ producing higher recoveries. Also, when using high stirring speed (maximum speed) instead of low (minimum speed) (maintaining remaining parameters at same levels), an increase or similar recoveries were, in general, observed. Also, $X_{2} X_{3}$ reached statistical significance $(p<0.05)$ with $20 \mathrm{~mL}$ of solvent and temperatures in the range $100-130{ }^{\circ} \mathrm{C}$ attaining bestresults.

Considering energy savings, $100{ }^{\circ} \mathrm{C}$ (minimum limit in the range) was the temperature chosen as optimum. Also, solvent volume lowest level $(20 \mathrm{~mL})$ and maximum stirring speed were undoubtedly the optimal conditions. Extraction time did not have a significant influence in OTA recovery $(p>0.05)$ however, as seen previously, its negative interaction with solvent volume reached significance. Therefore, considering energy and solvent saving concerns, lower/ 

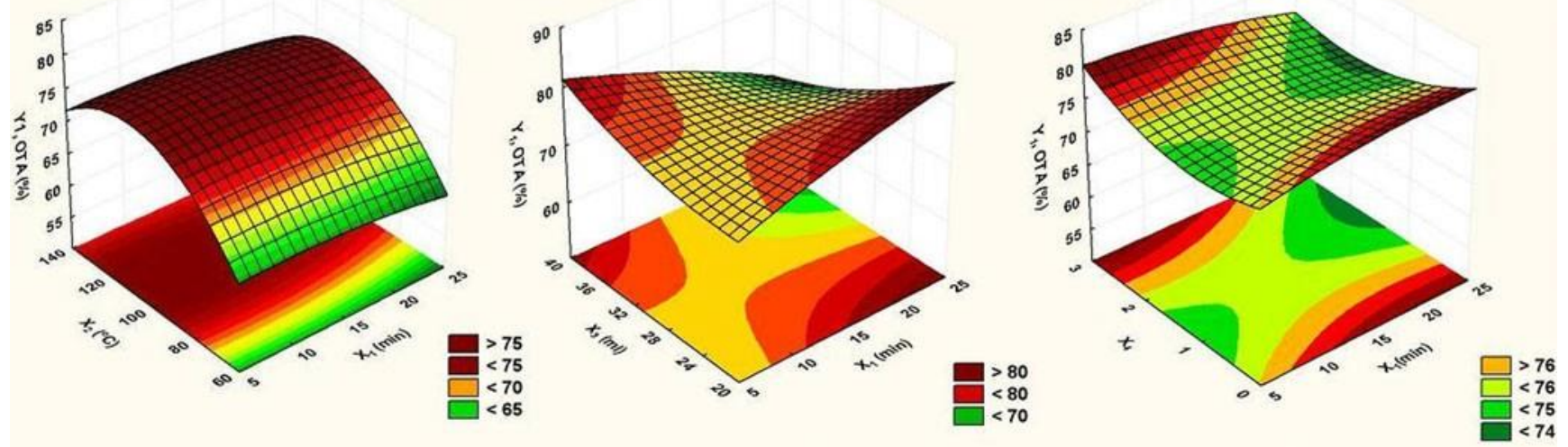

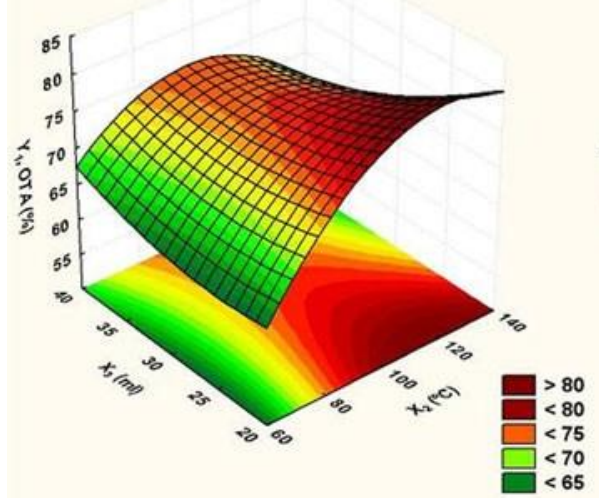

Fig. 1 Three-dimensional response surface showing OTA recovery $(\mathrm{Y} 1, \%)$ from "Carcaça" (wheat bread) spiked sample at $3.0 \mathrm{ng} / \mathrm{g}$ as a function of: extraction time $\left(X_{1} ; \min \right)$, temperature $\left(X_{2} ;{ }^{\circ} \mathrm{C}\right)$, solvent

upper range limits of solvent volume coupled with minimum extraction time (5 min) were studied in order to assess possible significant differences. The following sets of optimal conditions were tested: $5 \mathrm{~min}, 100{ }^{\circ} \mathrm{C}, 20 / 40 \mathrm{~mL}$, and maximum speed (sets A-B). Experimental run conditions leading to the highest recoveries $(\geq 79 \%)$ were also investigated (runs 2, 3, 5, 6, and 13 in Table 1; sets $\mathrm{C}-\mathrm{G}$, respectively). Five replicates were performed using these seven sets of operational parameters (set A: $5 \mathrm{~min}, 100{ }^{\circ} \mathrm{C}, 20 \mathrm{~mL}$ of solvent and maximum stirring speed; set B: $5 \mathrm{~min}, 100{ }^{\circ} \mathrm{C}, 40 \mathrm{~mL}$ of solvent and maximum stirring speed; set C: $10 \mathrm{~min}, 80{ }^{\circ} \mathrm{C}$, $25 \mathrm{~mL}$ of solvent and maximum stirring speed; set D: $10 \mathrm{~min}$, $80{ }^{\circ} \mathrm{C}, 35 \mathrm{~mL}$ of solvent and minimum stirring speed; set $\mathrm{E}$ : $10 \mathrm{~min}$ of extraction, $120^{\circ} \mathrm{C}, 25 \mathrm{~mL}$ of solvent and minimum stirring speed; set F: $10 \mathrm{~min}$ of extraction, $120^{\circ} \mathrm{C}, 25 \mathrm{ml}$ and maximum stirring speed; set G: 20 min of extraction, $120{ }^{\circ} \mathrm{C}$, $25 \mathrm{ml}$ and minimum stirring speed). A Student's $t$ test was applied, and no significant differences $(p>0.05)$ were found between the experimental runs results with highest recoveries (sets $\mathrm{C}-\mathrm{G}$ ) and so, the sets of conditions with lower value parameters (sets $\mathrm{C}$ and $\mathrm{D}$ ) were considered as possibleoptimal $(81.1 \pm 0.9$ for set $\mathrm{C}$ and $80.2 \pm 0.1 \%$ for set $\mathrm{D})$. The choice between sets $\mathrm{C}$ and $\mathrm{D}(25 \mathrm{~mL}$ of solvent/maximum speed of agitation vs. $35 \mathrm{ml}$ of solvent/ minimum speed of agitation) was made considering the solvent saving as being the most important. On the contrary, significant differences $(p<0.05)$ were found among treatments, when comparing the two sets chosen

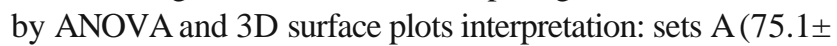
$3.3 \%)$ and B $(73.4 \pm 1.4 \%)$ with set $\mathrm{C}$ results. So, OTA recovery optimum conditions were considered to be the operational conditions used in run 2 (set C: $10 \mathrm{~min}$ of extraction, $80{ }^{\circ} \mathrm{C}, 25 \mathrm{~mL}$ of solvent and maximum stirring speed). As expected, OTA recoveries attained with sets A and B were low and close to the mean when compared with remain tested sets of conditions. This can be explained by the low quadratic correlation coefficient $R^{2}$ of the regression model as for $R^{2}$ values close to 1 occur when there is a perfect model adjustment to the experimental data and $R^{2}$ close to 0 means that the fit predicts no better than the mean response.

Custom Model Building The successful application of RSM tools in many optimization problems rely on the good explanation given by polynomial models (first and second orders; Eqs. 1 and 2, respectively) of the true relation between 
the studied response and the operational parameters. Full factorial are the most popular designs described by first-order models (Eq. 1) as they usually constitute a good first approach to the optimization problem allowing to detect the main effects as well as the second order-factor interactions $\left(X_{\mathrm{i}} X_{\mathrm{j}}\right)$ that most influence the response. In most of the cases, this linear model is not sufficient to represent an accurate relation between the studied variables and additional experiments are performed to obtain designs of higher complexity, such as central composite designs (CCD). CCD are described by second order polynomial equations (Eq. 2) that most often give an excellent approximation of how the response and dependent variables are related (Montgomery, 2005; Tarley et al. 2009).

In this study, RSM was a useful mechanism to achieve OTA recovery optimum conditions yet, more complex relationships between independent and dependent variables can explain some of the problems observed during the modelization process, namely, the low value of $R^{2}$ of the regression model (Eq. 3). For further investigation of the influence of higher-order interaction and polynomial effects in OTA recovery model, experimental results from the full factorial design (runs 1-16 in Table 1) and CCD (runs 1-25 in Table 1) were adjusted using, respectively, factorial and polynomial regressions with third-order terms. Finally, a more complex model was constructed including both kinds of interactions. Proper cautions were taken and the new models adequacy was checked by the adjusted $R^{2}$ as well as by comparison of the error of the squares between the former and the new models. The adjusted $R^{2}$ has the advantage of not increasing automatically as new regressors are inserted in the model. Also, the error of the squares (SS residual) in the new model must be reduced by an amount equal to the original error mean square (MS residual) otherwise, the new model will have a larger error mean square than the old one because of the loss of one residual degree of freedom (DF) and the new model will actually be worse than the old one (Montgomery 2005).

Results of the custom model building are described in Table 2. By adding higher order effects to the model, factorial, and/or polynomial, a significant increase in the quadratic correlation coefficient and adjusted $R^{2}$ was verified and the difference between the residual SS of the new and the old models suffered a decrease higher than the residual MS of the old model times the DF loss. For instance, by considering third-order factorial interactions $\left(X_{\mathrm{i}} X_{\mathrm{j}} X_{\mathrm{k}}\right)_{2}$ and polynomial effects $\left(X_{\mathrm{i}}\right)$ in the regression model both $R$ and adjusted $R$ increased dramatically ( 0.5415 vs. 0.8751 and 0.443 vs. 0.8277 , respectively) at the same time. In spite of losing eighteen DL the residual SS of the new model ( $Y_{1, \mathrm{e}}$ in Table 2$)$ suffered a decrease of 723 when compared with the residual SS of the old model ( $Y_{1, \mathrm{c}}$ in Table 2 ; regression model used during the optimization process), and this value was clearly higher than the 272 minimum limit necessary to state the new model's quality (lost DF times MS residual of $Y_{1, \mathrm{c}}$ ). Therefore, it can be concluded that more complex interactions between the studied process variables were not covered by the second order regression model obtained through the use of the $2^{4}$ orthogonal composite design and RSM explaining the previous low correlation coefficientobserved.

OTA Recovery for Different Spiking Levels As the OTA concentration level can affect the efficiency of the extraction, the optimal parameters of MAE (extraction at $80{ }^{\circ} \mathrm{C}$ for 10 minutes, maximum stirring, using $25 \mathrm{~mL}$ of acetonitrile and $5 \mathrm{~g}$ of bread sample) reached by the statistical analysis for the spiking level of $3.0 \mathrm{ng} / \mathrm{g}$ were applied to wheat bread samples fortified at four other levels $(0.033-2 \mathrm{ng} / \mathrm{g})$. The obtained recovery values were $80.8 \pm 2.6 \%, 79.3 \pm 2.9 \%$; $87.0 \pm 2.7 \%$, and $85.7 \pm 2.6 \%$, for spiking levels of 0.033 , $0.077,0.10$, and $2.00 \mathrm{ng} / \mathrm{g}$, respectively. These values may be considered adequate for OTA analysis in the bread samples and are consistent with recoveries reported for OTA extraction from bread samples using IAC clean-up (between 80.4-102.0\% for fortification levels at 0.5 and $0.033 \mathrm{ng} / \mathrm{g}$ (Juan et al. 2007) and in the range 78-89\% for samples spiked at $10 \mathrm{ng} / \mathrm{g}$ with a RSD03.7 \% (Juan et al. 2008a).

\section{Application to Bread Samples}

The optimized method of extraction was applied for OTA determination in 64 bread samples. The results are shown in Table 4. OTA contamination in the analyzed samples was

Table 4 OTA contents in the analysed bread samples

\begin{tabular}{|c|c|c|c|c|c|c|}
\hline Bread type & No. of samples & $\begin{array}{l}\text { No. of positive } \\
\text { samples }\end{array}$ & $\begin{array}{l}\text { Range of } \\
\text { concentrations }^{\mathrm{a}}(\mathrm{ng} / \mathrm{g})\end{array}$ & $\begin{array}{l}\text { Overall mean } \pm \text { S.D. } \\
(\mathrm{ng} / \mathrm{g})\end{array}$ & $\begin{array}{l}\text { Mean } \pm \text { S.D. } \\
(\mathrm{ng} / \mathrm{g})\end{array}$ & $\begin{array}{l}\text { Median }^{\mathrm{a}} \\
\text { (ng/g) }\end{array}$ \\
\hline "Carcaça" (Wheat bread) & 25 & 18 & $0.03-0.27$ & $0.11 \pm 0.09$ & $0.15 \pm 0.07$ & 0.15 \\
\hline \multicolumn{7}{|l|}{ "Broa de Milho" } \\
\hline (Maize bread) & 17 & 15 & $0.06-1.09$ & $0.28 \pm 0.25$ & $0.32 \pm 0.32$ & 0.16 \\
\hline \multicolumn{7}{|l|}{ "Broa de Avintes" } \\
\hline (Half maize half rye bread) & 22 & 21 & $0.03-2.09$ & $0.56 \pm 0.61$ & $0.58 \pm 0.61$ & 0.21 \\
\hline
\end{tabular}

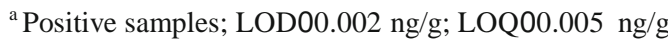



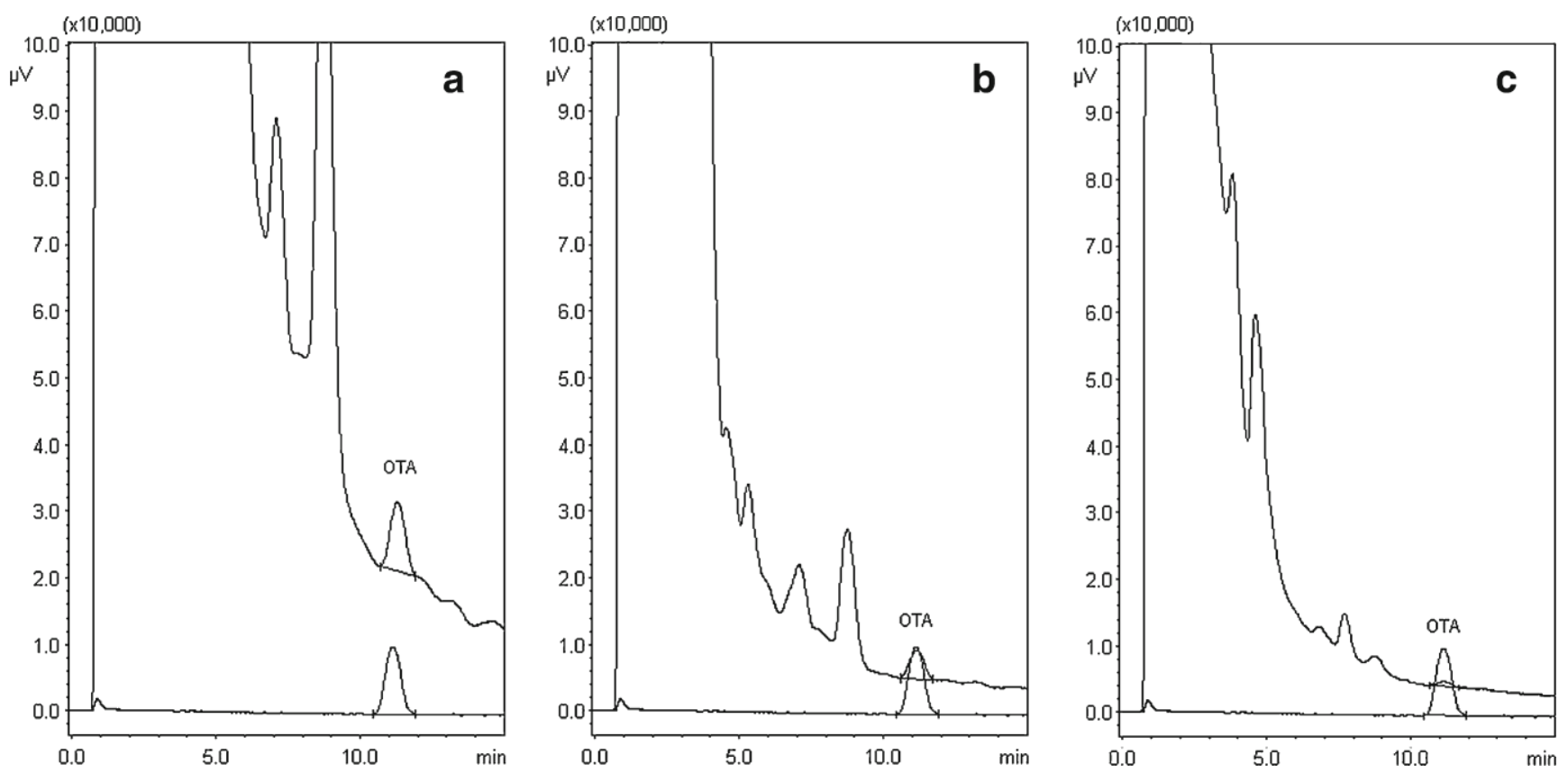

Fig. 2 Overlay chromatograms of OTA standard solution $(10 \mu \mathrm{g} / \mathrm{L})$ and bread sample extracts: a "Broa de Avintes" (maize and rye bread), b "Broa de Milho" (maize bread), and c "Carcaça" (wheat bread)

dependent on the bread type. As regards wheat bread, OTA was detected in $72 \%$ of the samples with a maximum value of $0.27 \mathrm{ng} / \mathrm{g}$. The OTA mean level in the contaminated samples was $0.15 \pm 0.07 \mathrm{ng} / \mathrm{g}$. Figure 2 shows representative chromatograms of OTA standard solution and bread sample extracts for the three types of bread analyzed. Figure 3 shows a comparison between the OTA values that are obtained using external standard calibration vs. standard addition. It can be seen that wheat bread presents the smallest matrix interference by contrast to maize/rye bread samples (Fig. 2 and Fig. 3).

Maize bread is a traditional and special type of bread very appreciated in Portugal, consumed mainly in the North and Central Zone of the country. This bread is made with cereals such as maize (Zea mays) and wheat (Triticum aestivum), where the ochratoxigenic moulds Aspergillus ochraceus and $P$. verrucosum, respectively, can grow. OTA was detected in $88.2 \%$ of the analyzed samples in the range n.d. $-1.09 \mathrm{ng} / \mathrm{g}$. OTA mean level was $0.32 \pm 0.32 \mathrm{ng} / \mathrm{g}$.
The traditional maize/rye bread ("broa de Avintes" showed higher contamination frequency $(95.4 \%)$ and contamination levels, between n.d. and $2.09 \mathrm{ng} / \mathrm{g}$ (average contamination $00.58 \pm 0.61 \mathrm{ng} / \mathrm{g}$ ). These results are in line with the ones reported in previous studies on OTA contamination of bread samples. Duarte et al. (2010b) concluded that a widespread low level of OTA contamination was observed in all Portuguese regions and types of bread products analyzed, especially in the Oporto and Coimbra regions, and in the maize and whole-grain or fibre-enriched bread.

\section{Conclusions}

This study reports an alternative method for the determination of OTA in bread samples by microwave assisted extraction and LC-FD analysis. Extraction conditions were
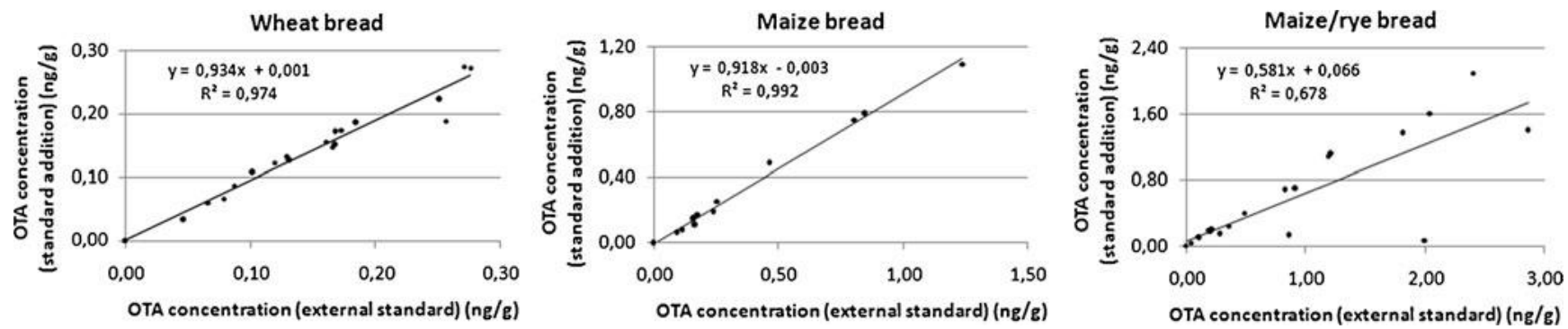

Fig. 3 Quantification of OTA on the bread samples: external standard vs. standard addition 
optimized using a $2^{4}$ orthogonal composite design coupled with response surface methodology in order to study the influence of MAE parameters (extraction time, temperature, solvent volume, and stirring speed). The method has demonstrated to be accurate, with recoveries in the range 79.3$87 \%$, for fortification levels between 0.033 and $3.0 \mathrm{ng} / \mathrm{g}$, and precise $(\mathrm{RSD}<3.0 \%)$. The method was applied to 64 bread samples that cover the types of bread that are the most consumed in Portugal (wheat, maize, and maize/rye bread). None of the samples exceeded the legal European limit of $3 \mathrm{ng} / \mathrm{g}$ for cereal based products. However, maize-based breads seem to present higher OTA levels.

Acknowledgements The authors are grateful to FCT-Fundação para a Ciência e Tecnologia, for supporting this work through the Project PTDC/AGR-ALI/65528/2006.

Disclaimers The authors state the nonexistence of any financial/ commercial conflicts of interest. The author's affiliation is as shown on the cover page. The submission to this journal is approved by all authors who alone are responsible for the content and writing of the manuscript.

Funding FCT-Fundação para a Ciência e Tecnologia supported this work through the Project PTDC/AGR-ALI/65528/2006.

\section{References}

Ali, W. H., Derrien, D., Alix, F., Pérollier, C., Lépine, O., Bayoudh, S., Chapuis-Hugon, F., \& Pichon, V. (2010). Solid-phase extraction using molecularly imprinted polymers for selective extraction of a mycotoxin in cereals. Journal of Chromatography. A, 1217(43), 6668-6673.

Domingos, A. K., Saad, E. B., Wilhelm, H. M., \& Ramos, L. P. (2008). Optimization of the ethanolysis of Raphanus sativus (L.Var.) crude oil applying the response surface methodology. Bioresource Technology, 99(6), 1837-1845.

Duarte, S. C., Pena, A., \& Lino, C. M. (2010a). A review on ochratoxin A occurrence and effects of processing of cereal and cereal derived food products. Food Microbiology, 27(2), 187-198.

Duarte, S. C., Bento, J., Pena, A., Lino, C. M., Delerue-Matos, C., Oliveira, M. B. P. P., Alves, M. R., \& Pereira, J. A. (2010b). Influencing factors on bread-derived exposure to ochratoxin A: type, origin and composition. Food and Chemical Toxicology, 48 (8-9), 2139-2147.

Duarte, S. C., Silva, L. J. G., Lino, C. M., \& Pena, A. (2011). Food analysis of ochratoxin A and fumonisins B1 and B2: state-of-theart. In Medina \& Laine (Eds.), Food Quality: Control, Analysis and Consumer Concerns (pp. 61-130). New York: Nova Science Publishers, Inc.

EC-European Commission (2005). Commission regulation No 123/ 2005 of 26 January 2005 amending regulation (EC) No 466/2001 as regards ochratoxin A. Official Journal of the European Communities, L-25, 3-5.

Elmholt, S., \& Rasmussen, P. H. (2005). Penicillium verrucosum occurrence and Ochratoxin A contents in organically cultivated grain with special reference to ancient wheat types and drying practice. Mycopathologia, 159(3), 421-432.
EFSA-European Food Safety Authority (2006). Opinion of the scientific panel on contaminants in the food chain on a request from the commission (Question no. EFSA-Q-2005154) related to ochratoxin A in food. The EFSA Journal, L$365,1-56$.

García-Fonseca, S., Ballesteros-Gómez, A., Rubio, S., \& Pérez-Bendito, D. (2010). Supramolecular solvent-based microextraction of ochratoxin $\mathrm{A}$ in raw wheat prior to liquid chromatographyfluorescence determination. Journal of Chromatography. A, 1217(16), 2376-2382.

Garg, U. K., Kaur, M. P., Garg, V. K., \& Sud, D. (2008). Removal of Nickel (II) from aqueous solution by adsorption on agricultural waste biomass using a response surface methodological approach. Bioresource Technology, 99(5), 1325-1331.

González-Osnaya, L., Soriano del Castillo, J. M., Moltó Cortés, J. C., \& Mañes Vinuesa, J. (2006). Extraction and analysis of ochratoxin $\mathrm{A}$ in bread using pressurised liquid extraction and liquid chromatography. Journal of Chromatography. A, 1113(1-2), 3236.

González-Osnaya, L., Soriano, J. M., Moltó, J. C., \& Mañes, J. (2007). Dietary intake of ochratoxin A from conventional and organic bread. International Journal of Food Microbiology, 118(1), 8791.

IARC-International Agency for Research on Cancer (1993). Some naturally occurring substances, food items and constituents, heterocyclic aromatic amines and mycotoxins. Monograph no. 56. IARC, Lyon, France.

INE—Instituto Nacional de Estatística (2008). Estatísticas da produção industrial 2006, Lisboa, Portugal. Available at: http://www.ine.pt/ ine/acess/pub_detalhe.jsp?boui_aux016671129. Accessed 12 June 2008.

JECFA-Joint FAO/WHO Expert Committee on Food Additives (2007). Safety evaluations of specific mycotoxins: Ochratoxin A. Prepared by the 56th Meeting, 6-15 February 2007, Genéve, Switezerland.

Juan, J., Lino, C. M., Pena, A., Moltó, J. C., Mañes, J., \& Silveira, I. (2007). Determination of ochratoxin A in maize bread samples by LC with fluorescence detection. Talanta, 73(2), 246-250.

Juan, C., Moltó, J. C., Lino, C. M., \& Mañes, J. (2008a). Determination of ochratoxin A in organic and non-organic cereals and cereal products from Spain and Portugal. Food Chemistry, 107(1), 525-530.

Juan, C., Pena, A., Lino, C., Moltó, J. C., \& Mañes, J. (2008b). Levels of ochratoxin A in wheat and maize bread from the central zone of Portugal. International Journal of Food Microbiology, 127(3), 284-289.

Liazid, A., Palma, M., Brigui, J., \& Barroso, C. G. (2007). Investigation on Ochratoxin A stability using different extraction techniques. Talanta, 71(2), 976-980.

Lundstedt, T., Seifert, E., Abramo, L., Thelin, B., Nystrom, A., Pettersen, J., \& Bergman, R. (1998). Experimental design and optimization. Chemometrics and Intelligent Laboratory Systems, 42 (1-2), 3-40.

Manique, R., Pena, A., Lino, C. M., Moltó, J. C., \& Mañes, J. (2008). Ochratoxin A in the morning and afternoon portions of urine from Coimbra and Valencian populations. Toxicon, 51(7), 1281-1287.

Masmoudi, M., Besbes, S., Chaabouni, M., Robert, C., Paquot, M., Blecker, C., \& Attia, H. (2008). Optimization of pectin extraction from lemon by-product with acidified date juice using response surface methodology. Carbohydrate Polymers, 74(2), 185-192.

Miller, J. C., \& Miller, J. N. (1989). Statistics for analytical chemistry (2nd ed.). New York: John Wiley and Sons.

Montgomery, D. C. (2005). Design and analysis of experiments: response surface method and designs. New Jersey: John Wiley and Sons Inc.

Paíga, P., Morais, S., Correia, M., Alves, A., \& Delerue-Matos, C. (2008). A multiresidue method for the analysis of carbamate and 
urea pesticides from soils by microwave-assisted extraction and liquid chromatography with photodiode array detection. Analytical Letters, 41(10), 1751-1772.

Paíga, P., Morais, S., Correia, M., Delerue-Matos, C., \& Alves, A. (2009). Determination of carbamate and urea pesticide residues in vegetables using microwave-assisted extraction and liquid chromatography. International Journal of Environmental Analytical Chemistry, 89(3), 199-210.

Pallaroni, L., \& von Holst, C. (2003). Comparison of alternative and conventional extraction techniques for the determination of zearalenone in corn. Analytical and Bioanalytical Chemistry, 376(6), 908-912.

Pallaroni, L., von Holst, C., Eskillson, C. S., \& Björklund, E. (2002). Microwave-assisted extraction of zearalenone from wheat and corn. Analytical and Bioanalytical Chemistry, 374(1), 161-166.

Pelegri, J. M., Velazquez, C., Sanchis, V., \& Canela, R. (1997). Solid phase extraction on sax columns as an alternative for ochratoxin A analysis in maize. Revista Iberoamerica de Micologia, 14(4), 194-196.
Sun, L., \& Lee, H. K. (2002). Microwave-assisted extraction behaviour of non-polar and polar pollutants in soil with analysis by highperformance liquid chromatography. Journal of Separation Science, 25(1-2), 67-76.

Tarley, C. R. T., Silveira, G., dos Santos, W. N. L., Matos, G. D., Silva, E. G. P., Bezerra, M. A., Miró, M., \& Ferreira, S. L. C. (2009). Chemometric tools in electroanalytical chemistry: methods for optimization based on factorial design and response surface methodology. Microchemical Journal, 92(1), 58-67.

Turner, N. W., Subrahmanyam, S., \& Piletsky, S. A. (2009). Analytical methods for determination of mycotoxins: a review. Analytica Chimica Acta, 632(2), 168-180.

Vega, M., Muñoz, K., Sepúlveda, C., Aranda, M., Campos, V., Villegas, R., \& Villarroel, O. (2009). Solid-phase extraction and HPLC determination of ochratoxin $\mathrm{A}$ in cereals products on Chilean market. Food Control, 20(7), 631-634.

Zinedine, A., Juan, C., Idrissi, L., \& Mañes, J. (2007). Occurrence of ochratoxin A in bread consumed in Morocco. Microchemical Journal, 87(2), 154-158. 